\title{
Alterações morfológicas no sistema radicular do milho induzidas por fungos micorrízicos e fósforo(1)
}

\author{
Wellington Bressan ${ }^{(2)}$ e Carlos Alberto Vasconcellos ${ }^{(2)}$
}

\begin{abstract}
Resumo - O objetivo deste trabalho, conduzido em casa de vegetação, foi avaliar os efeitos da inoculação de fungos micorrízicos arbusculares (Glomus etunicatum e Glomus clarum) e da adição de níveis de $\mathrm{P}$ $(0,50,100$ e $200 \mathrm{mg} / \mathrm{kg}$ de solo) sobre a morfologia do sistema radicular do milho (Zea mays L.), cultivar BR 201, e a concentração de P na planta, em duas épocas de colheita (18 e 104 dias após semeadura) em solo Latossolo Vermelho-Escuro distrófico desinfestado com Bromex. O experimento foi realizado na Embrapa-Centro Nacional de Pesquisa de Milho e Sorgo, Sete Lagoas, MG. A inoculação de fungos micorrízicos aumentou o peso das raízes secas, o número de raízes laterais primárias e secundárias, e o teor de $\mathrm{P}$ na planta, porém reduziu a relação peso das raízes secas/peso da parte aérea seca e o número de pêlos radiculares. Esses efeitos foram dependentes das doses de $\mathrm{P}$ aplicadas ao solo e da espécie de fungo micorrízico. O peso das raízes secas das plantas micorrizadas mostrou correlação significativa $(\mathrm{P} \leq 0,05)$ com a colonização micorrízica, nas raízes seminais e adventícias, e o número de raízes laterais primárias e secundárias das plantas micorrizadas mostrou correlação significativa $(\mathrm{P} \leq 0,05)$ com a colonização micorrízica. Glomus etunicatum foi mais eficiente no aumento do peso das raízes secas, do número de raízes laterais primárias e secundárias e no aumento do teor de $\mathrm{P}$ na planta, em todas as doses de P; entretanto, doses altas de P reduziram esses efeitos das duas espécies de fungos, como conseqüência da redução da colonização micorrízica.
\end{abstract}

Termos para indexação: micorriza, inoculação, concentração

Morphological alterations on root system of maize induced by mycorrhizal fungi and phosphorus

Abstract - The objective of this research, carried out under greenhouse conditions was to evaluate the effect of mycorrhizal fungi (Glomus etunicatum and Glomus clarum) inoculation and P levels $(0,50$, 100 e $200 \mathrm{mg} / \mathrm{kg}$ of soil) on maize (Zea mays L.) root system morphology, cultivar BR 201, and P plant concentration in two harvest period (18 and 104 days after sowing) in disinfested dystrophic Dark-Red Latosol. The experiment was carried out under greenhouse conditions at Embrapa-Centro Nacional de Pesquisa de Milho e Sorgo, in Sete Lagoas, Minas Gerais, Brazil. Inoculation with mycorrhizal fungi increased root dry weight, number of first and second order lateral roots and $\mathrm{P}$ concentration in the plant, but decreased root/shoot dry weight ratio and number of root hairs. These effects were affected by $\mathrm{P}$ concentration in the soil and by mycorrhizal fungi species. Root dry weight of inoculated plants showed significative $(\mathrm{P} \leq 0.05)$ correlation to root colonization to seminal and adventitious roots. Number of first and second orders lateral roots also showed significative $(\mathrm{P} \leq 0.05)$ correlation to root colonization. Glomus etunicatum was most efficient in all $\mathrm{P}$ levels, but high $\mathrm{P}$ levels reduced these effects for both fungi species due to reduction on mycorrhizal colonization.

Index terms: mycorrhizae, inoculation methods, concentrating.

\section{Introdução}

Fungos micorrízicos colonizam o sistema radicular da maioria das plantas, e um dos benefícios mais re-

(1) Aceito para publicação em 16 de julho de 2001.

(2) Embrapa-Centro Nacional de Pesquisa de Milho e Sorgo, Caixa Postal 151, CEP 35701- 970 Sete Lagoas, MG. E-mail: bressan@cnpms.embrapa.br, carlos@cnpms.embrapa.br latados tem sido a maior absorção de $\mathrm{P}$ pelas plantas micorrizadas (Hodge et al., 2000; Prasad et al., 2000). Entretanto, essa absorção tem sido relacionada às propriedades morfológicas das raízes da planta hospedeira (Karagiannidis \& Nikolaou, 1999). Plantas com poucos pêlos absorventes têm sido caracterizadas como altamente dependentes das associações micorrízicas. Por outro lado, o aumento dos pêlos 
absorventes diminui a dependência micorrízica (Price et al., 1989).

O crescimento e o desenvolvimento dos fungos micorrízicos são afetados pelo suprimento de $\mathrm{P}, \mathrm{o}$ qual é negativamente correlacionado com a colonização micorrízica das raízes. A infecção micorrízica aumenta com adição de baixos teores de $\mathrm{P}$ (Karagiannidis \& Nikolaou, 1990), ou é reduzida em altos teores de P (Guillemin et al., 1995; Al-Karaki \& Clark, 1999). Outro fator importante envolvendo os fungos micorrízicos e o teor de P no solo, são seus efeitos sobre a morfologia das raízes. O reduzido crescimento dos pêlos absorventes e o reduzido comprimento radicular do milho com inoculação de fungos micorrízicos estão relacionados negativamente com a concentração de $\mathrm{P}$ nos tecidos das plantas (Kothari et al., 1990). Entretanto, alguns trabalhos mostraram que inoculação com fungos micorrízicos aumenta a produção de raízes (Hodge et al., 2000), o peso total de raízes (Mane et al., 1993; Hernandez \& Cardenas, 1994) e o comprimento das raízes (Isopi et al., 1995). Berta et al. (1990) verificaram que em Allium porrum a inoculação de fungos micorrízicos aumentou o número de raízes adventícias mas reduziu o seu tamanho em relação às plantas não micorrizadas. Além disso, as raízes micorrizadas tornaram-se mais ramificadas.

O comprimento total das raízes é estimulado pelo P (Elwan, 1993) enquanto a colonização radicular por comprimento de raiz pode ou não ser influenciada pelo P (Thomson et al., 1990). Esse aumento no comprimento total das raízes pode estar relacionado a aumento no número de ápices produzidos por unidade de comprimento das raízes e/ou ao aumento da extensão desses ápices (Bruce et al., 1994). Os efeitos da inoculação de fungos micorrízicos e da aplicação de P sobre a morfologia do sistema radicular e o teor de $\mathrm{P}$ na planta de milho ainda é pouco estudado.

O objetivo deste trabalho foi verificar o efeito da inoculação de fungos micorrízicos e adição de $\mathrm{P}$ ao solo, na morfologia radicular e no teor de $\mathrm{P}$ foliar no milho.

\section{Material e Métodos}

O experimento foi realizado em casa de vegetação na Embrapa-Centro Nacional de Pesquisa de Milho e Sorgo,
Sete Lagoas, MG. O delineamento experimental usado foi o completamente casualizado em fatorial $(3 \times 4 \times 2)$ sendo duas espécies de fungos micorrízicos arbusculares (Glomus etunicatum INVAM 3129 e Glomus clarum) e o tratamento sem inoculação, quatro doses de $\mathrm{P}(0,50,100 \mathrm{e}$ $200 \mathrm{mg} / \mathrm{kg}$ de solo) e duas épocas de colheita (18 e 104 dias após semeadura), com cinco repetições.

O solo utilizado foi um Latossolo Vermelho-Escuro distrófico, sob vegetação de cerrado, coletado na profundidade de 0-20 cm, cuja análise apresentou os seguintes resultados: pH em água (1:25), 5,1; $\mathrm{H}+\mathrm{Al}, 7,92 \mathrm{cmol}_{\mathrm{c}} / \mathrm{dm}^{3}$; $\mathrm{Al}, 0,80 \mathrm{cmol}_{\mathrm{d}} / \mathrm{dm}^{3} ; \mathrm{Ca}, 1,70 \mathrm{cmol}_{\mathrm{c}} / \mathrm{dm}^{3} ; \mathrm{Mg}, 0,33 \mathrm{cmol}_{\mathrm{d}} / \mathrm{dm}^{3}$; $\mathrm{K}, 43 \mathrm{mg} / \mathrm{dm}^{3} ; \mathrm{P}, 4,0 \mathrm{mg} / \mathrm{dm}^{3} ; \mathrm{MO}, 43,1 \mathrm{~g} / \mathrm{kg}$ e saturação de Al, 27\%. O solo peneirado, homogeneizado e desinfestado com Bromex (brometo de metila + cloropicrina $2 \%$ ) na dose de $100 \mathrm{~cm}^{3} / \mathrm{m}^{3}$ de solo, recebeu calcário dolomítico Supermil $(\mathrm{PRNT}=95 \%)$ suficiente para elevar o $\mathrm{pH}$ para 6,0 e colocado em recipientes para $16 \mathrm{~kg}$ de solo. Após a adição de calcário foi efetuada a adubação com nitrato de amônio, superfosfato simples, cloreto de potássio e FTE BR12 $(0,05 \mathrm{~g} / \mathrm{kg}$ de solo).

A semeadura foi realizada com cinco sementes de milho, cultivar BR 201, e o desbaste, efetuado aos 15 dias após a semeadura, deixando-se uma planta por vaso. A inoculação de fungos micorrízicos foi efetuada aplicando-se $10 \mathrm{~mL}$ de uma suspensão de esporos contendo 500 esporos por vaso. Os vasos sem inoculação com fungos micorrízicos receberam $30 \mathrm{~mL} /$ vaso de um filtrado dos inóculos provenientes do solo utilizado na multiplicação dos fungos

A irrigação dos vasos foi realizada em função da necessidade baseando-se no peso dos vasos, mantendo-se $60 \%$ do volume total de poros preenchidos com água. As condições de casa de vegetação foram: temperatura $28 \pm 3^{\circ} \mathrm{C}$, e luminosidade média de $625 \mu$ eisteins $/ \mathrm{m}^{2} / \mathrm{seg}$. Cinco plantas de cada tratamento nos períodos de $18 \mathrm{e}$ 104 dias foram colhidas, lavadas com água, para a remoção do solo, e separadas a parte aérea das raízes para a determinação do peso da parte aérea e raízes secas. Os pesos da matéria seca da parte aérea e das raízes foram obtidos pela secagem em estufa a $65^{\circ} \mathrm{C}$ até peso constante, e utilizados para o cálculo da relação raiz/parte aérea $(\mathrm{R} / \mathrm{S})$. Da matéria seca da parte aérea obtiveram-se os extratos para a determinação do $\mathrm{P}$ após digestão nitroperclórica (Sarruge \& Haag, 1974). O número de raízes seminais e adventícias (nodais e laterais de primeira ordem) foram contadas, e o número de pêlos absorventes foram determinados segundo Kothari et al. (1990). A porcentagem de colonização micorrízica foi determinada segundo Giovanetti \& Mosse (1980), após clarificação com $\mathrm{KOH}$ e coloração com azul de tripano segundo Phillips \& Hayman (1970). 
$\mathrm{Na}$ análise dos dados usou-se o programa MSTAT-C (Michigan State University,1989) e as médias foram comparadas pelo teste de Duncan. Os dados referentes à porcentagem de colonização das raízes foram transformados por arco seno antes de serem analisados estatisticamente.

\section{Resultados e Discussão}

O peso das raízes seminais secas (PS) e adventícias secas (PA) aumentou com as doses de $\mathrm{P}$, tanto nas plantas micorrizadas quanto nas não micorrizadas (Figura 1). Nas plantas micorrizadas com Glomus etunicatum, os pesos máximos das raízes foram obtidos com as aplicações de P nos níveis 171 e $158 \mathrm{mg} / \mathrm{kg}$, respectivamente, nas raízes seminais e nas adventícias. Nas plantas micorrizadas com Glomus clarum, os valores máximos de PS e PA foram obtidos com as aplicações de P nos níveis 1.178 e $198 \mathrm{mg} / \mathrm{kg}$ de solo. Nas plantas não micorrizadas, o peso máximo foi obtido nas doses de P com 246 e $235 \mathrm{mg} / \mathrm{kg}$ de solo. Nessas doses de P, a inoculação de Glomus etunicatum aumentou o peso da matéria seca em $21,2 \%$ e $32,4 \%$, respectivamente, no PS e PA, em relação às plantas sem inoculação. Nas plantas com Glomus clarum, verificou-se um aumento de $3,0 \% \mathrm{e}$ $16 \%$ no PS e PA. Comparadas com as plantas sem inoculação, as micorrizadas apresentaram maior PS e PA, em todas as doses de P; entretanto, nessas plantas, doses de $\mathrm{P}$ acima das que levaram ao máximo peso das raízes reduziram o PS e o PA. O peso da matéria seca das raízes das plantas micorrizadas mostrou correlação significativa positiva $(\mathrm{P} \leq 0,05)$ com a colonização micorrízica: $r=0,646$ e $r=0,471$, respectivamente para as raízes seminais e adventícias.

Nas plantas, com ou sem inoculação, a relação R/S foi inversa à aplicação de P (Figura 1). Nas plantas sem inoculação, 0 aumento das doses de $\mathrm{P}$ aumentou o peso da matéria seca das raízes, o número de raízes laterais e pêlos radiculares (Figura 2), levando a um maior teor de P na parte aérea (Figura 3), e, conseqüentemente, a um maior peso da parte aérea. Nas plantas infectadas com fungos micorrízicos ocorreu um menor número de pêlos radiculares, porém as hifas micorrízicas supriram suficientemente as plantas com $P$, aumentando o peso da parte aérea e reduzindo a relação R/S. Doses altas de P tiveram um efeito inibitório sobre os fungos micorrízicos, reduzindo a colonização micorrízica (Figura 4), o teor de P na par- te aérea, e o PA. Entretanto, essa redução no PA não afetou significativamente a relação $\mathrm{R} / \mathrm{S}$, mas resultou em uma estabilização da relação $\mathrm{R} / \mathrm{S}$ em doses altas de $\mathrm{P}$. O mesmo ocorreu com o peso das raízes, levando a uma tendência de estabilização da relação R/S. Nas plantas com 18 e 104 dias, verificou-se correlação significativa $(\mathrm{P} \leq 0,05)$ entre o peso da matéria seca das raízes e o da parte aérea, obtendo-se $r=0,78$ e $r=0,68$, respectivamente, para as plantas com 18 e 104 dias. O efeito positivo da inoculação sobre a relação $\mathrm{R} / \mathrm{S}$, na cebola, também foi verificado por Becker \& Gerdemann (1977).

Nas raízes seminais, o número de raízes laterais primárias variou com as doses de $\mathrm{P}$ (Figura 2a). Nas plantas micorrizadas, esse número aumentou até as doses de P nos níveis 139 e $285 \mathrm{mg} / \mathrm{kg}$ de solo, respectivamente, para as plantas com inoculação de Glomus etunicatum e Glomus clarum. Nestas doses de P, nas plantas com inoculação de Glomus etunicatum e Glomus clarum, o número máximo de raízes laterais primárias foi, respectivamente, de 88 e 128. A adição de $\mathrm{P}$ ao solo acima desses valores reduziu o número de raízes laterais primárias das plantas micorrizadas. Na dose de P equivalente a $200 \mathrm{mg} / \mathrm{kg}$ de solo, não houve diferença significativa no número de raízes laterais primárias entre as plantas com e sem inoculação. O número de raízes laterais secundárias (Figura 2b) mostrou comportamento semelhante em relação às doses de $\mathrm{P}$; entretanto, na dose de P igual a $200 \mathrm{mg} / \mathrm{kg}$ de solo, o número de raízes secundárias/planta foi maior nas plantas sem inoculação. Nas plantas com inoculação de Glomus etunicatum e Glomus clarum, o número máximo de raízes secundárias foi obtido nas doses de $\mathrm{P}$ nos níveis de 136 e $143 \mathrm{mg} / \mathrm{kg}$ de solo, respectivamente. $\mathrm{A}$ adição de $\mathrm{P}$ ao solo aumentou o número de raízes laterais primárias e secundárias do milho, porém o aumento pode variar com o tipo de cultura, como mostrado por Amijee et al. (1989), os quais, cultivando solanáceas, verificaram que o aumento das doses de $\mathrm{P}$ não afetou as raízes laterais primárias. A produção de novas raízes com adição de $\mathrm{P}$ também foi constatada em abóbora por Bruce et al. (1994). O número de raízes laterais primárias e secundárias das plantas micorrizadas mostrou uma correlação $(\mathrm{P} \leq 0,05)$ com a colonização micorrízica, sendo $r=0,74$ e $r=0,76$, respectivamente, para as raízes laterais primárias e secundárias. 
Nas raízes adventícias, o número de raízes laterais primárias (Figura 2d) e nodais (Figura 2e) foi influenciado pela adição de $\mathrm{P}$ ao solo e pela inoculação de fungo micorrízico. $\mathrm{O}$ número de raízes nodais/planta aumentou com a aplicação de $\mathrm{P}$ ao solo (Figura 2e), porém a inoculação de fungo micorrízico não mostrou efeito significativo em relação às plantas sem inoculação. $\mathrm{O}$ número de raízes laterais pri-
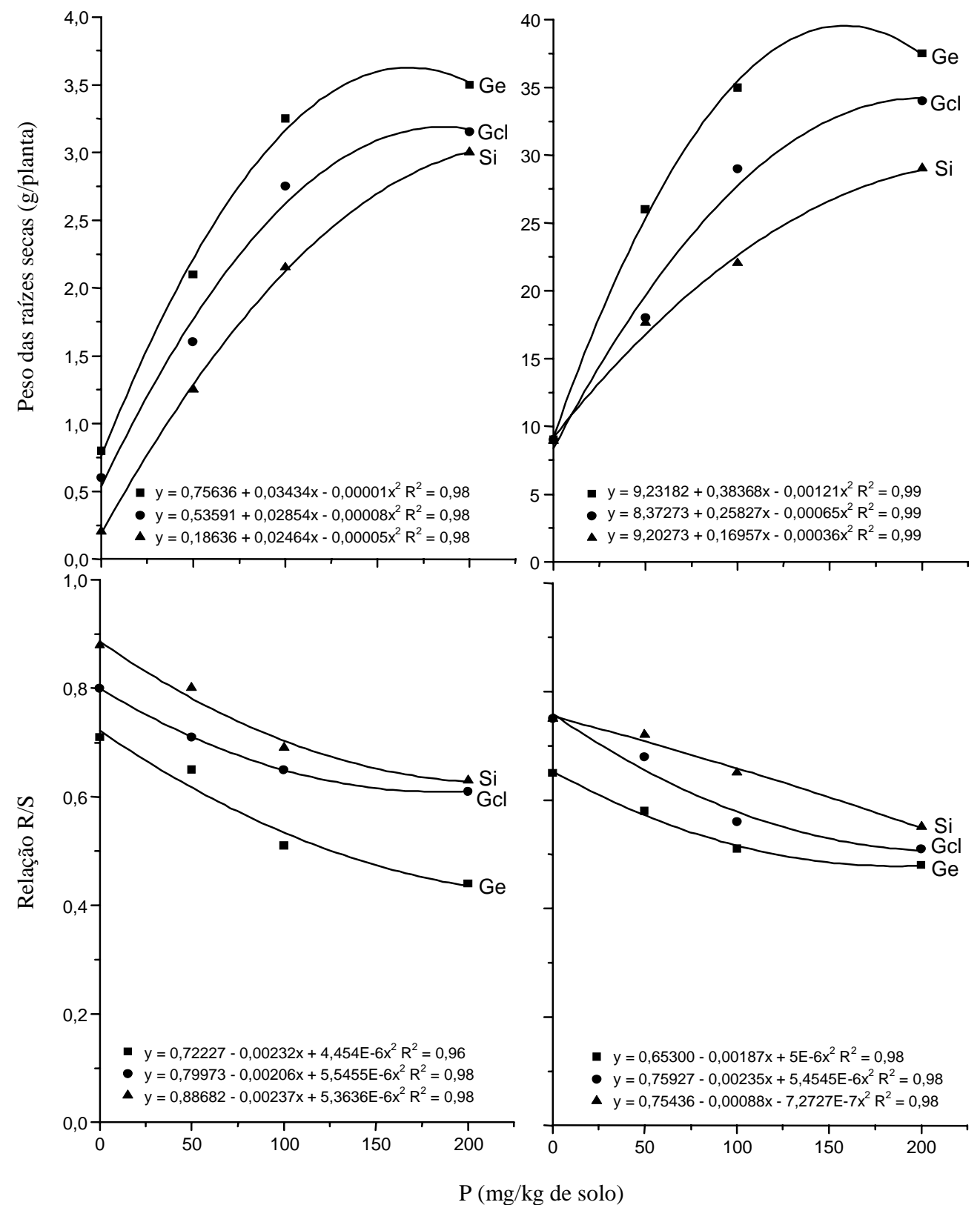

Figura 1. Efeitos de doses de $\mathrm{P}$ e da inoculação de fungos micorrízicos arbusculares sobre o peso das raízes secas e relação raiz/parte aérea (R/S) do milho. Ge (Glomus etunicatum), Gcl (Glomus clarum) e $\mathrm{Si}$ (sem inoculação). 
Raízes seminais
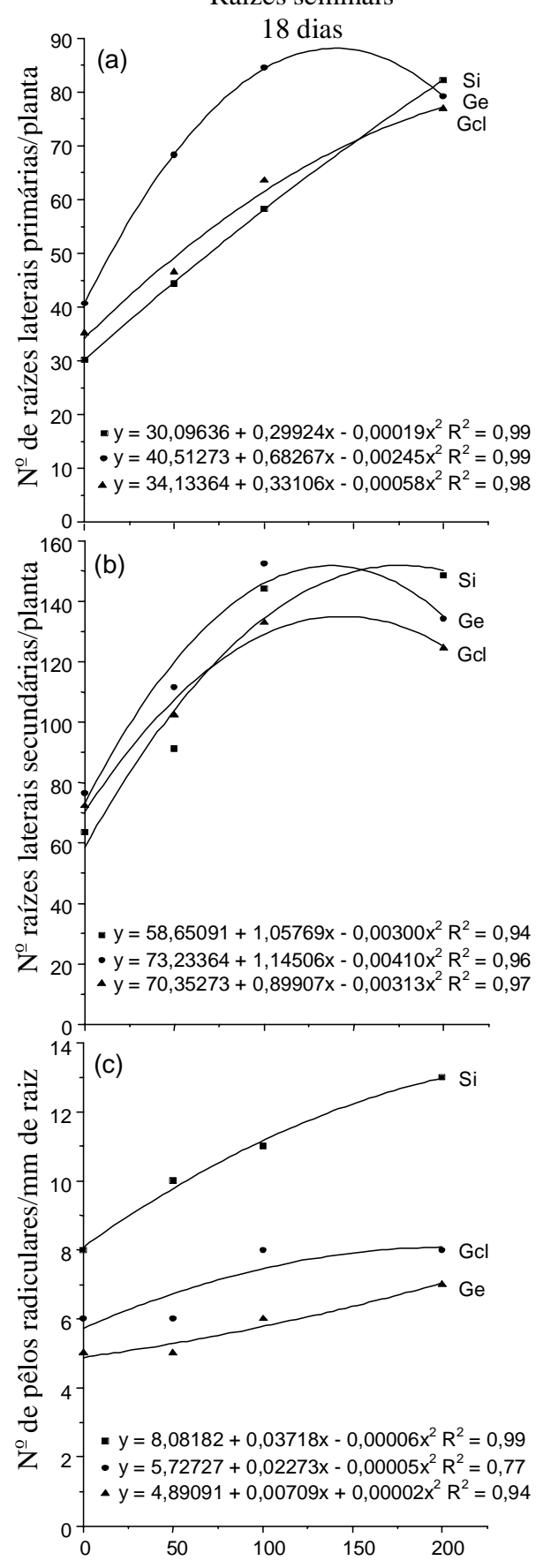

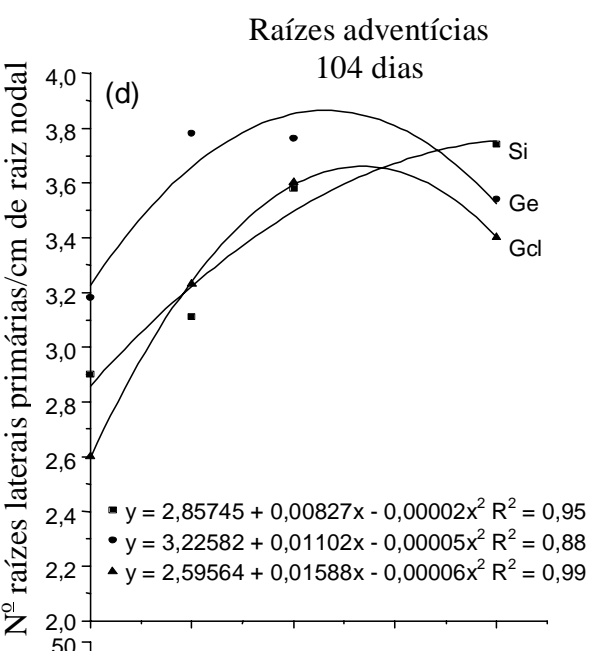

(e)
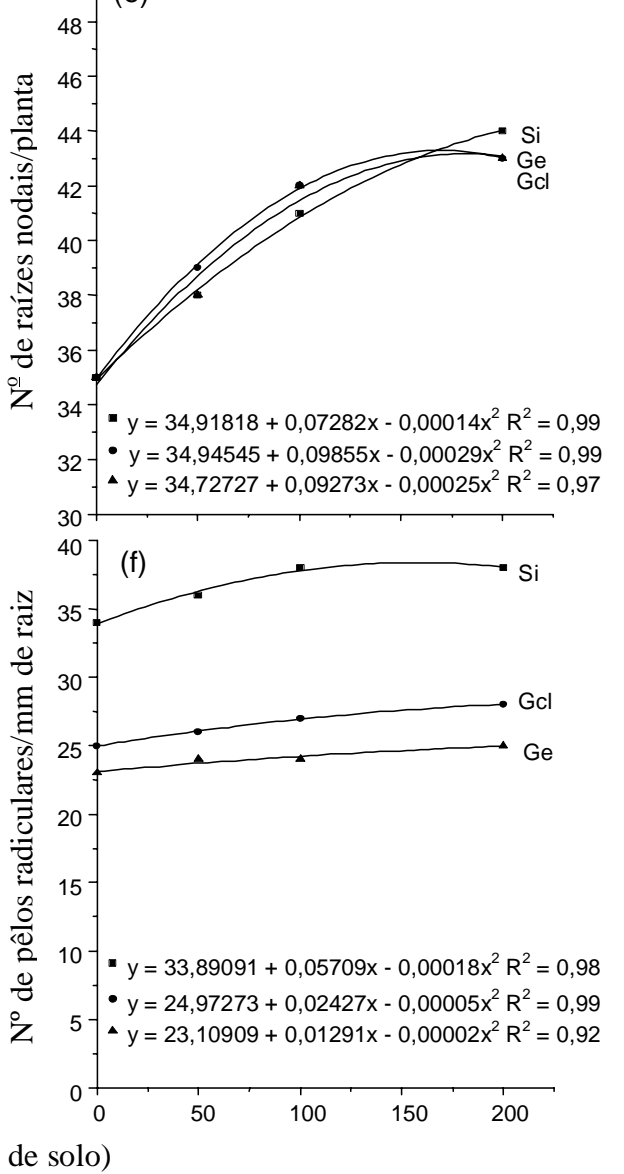

Figura 2. Número de raízes laterais primárias e secundárias, nodais e pêlos radiculares do milho em diferentes doses de $\mathrm{P}$ e com inoculação de fungos micorrízicos arbusculares. Ge (Glomus etunicatum), Gcl (Glomus clarum) e Si (sem inoculação). 
márias/cm de raiz nodal nas plantas micorrizadas aumentou até as doses de $\mathrm{P}$, equivalentes a $110 \mathrm{e}$ $132 \mathrm{mg} / \mathrm{kg}$ de solo, respectivamente, para Glomus etunicatum e Glomus clarum. Doses maiores reduziram o número de raízes laterais primárias nas plantas micorrizadas. As micorrizadas com Glomus etunicatum apresentaram maior número de raízes laterais/cm de raiz nodal. A inoculação de fungo micorrízico não afetou significativamente $(\mathrm{P} \leq 0,05)$ o número de raízes nodais, porém o número de raízes laterais primárias foi influenciado pela inoculação de fungo micorrízico e apresentou correlação $(\mathrm{P} \leq 0,05)$ com a colonização micorrízica $(\mathrm{r}=0,58)$. $\mathrm{O}$ peso das raízes adventícias (nodais + laterais) mostrou uma correlação $(\mathrm{P} \leq 0,05)$ com a colonização micorrízica $(r=0,57)$. Essa correlação é decorrente do efeito da inoculação (Figura 2d) sobre as raízes laterais primárias, visto que a inoculação não teve efeito significativo sobre as raízes nodais.

O número de pêlos radiculares/mm de raiz foi menor nas plantas infectadas com fungo micorrízico, tanto nas raízes seminais das plantas com 18 dias, como nas raízes adventícias das plantas com 104 dias (Figura 2c, 2f). Resultados semelhantes foram observados por Kothari et al. (1990) em plantas de milho micorrizadas. Considerando que a maior colonização micorrízica e o maior teor de P na planta foram observados na inoculação de Glomus etunicatum, a redução no número de pêlos absorventes pode estar relacionada, em parte, à concentração de $\mathrm{P}$ na planta, como verificado pela correlação negativa $(\mathrm{r}=0,62)$ entre o teor de $\mathrm{P}$ na planta e o número de pêlos absorventes. Logo, a função de aquisição de $\mathrm{P}$ pelos pêlos radiculares foi adequadamente efetuada pelo fungo micorrízico. Uma das vantagens das plantas micorrizadas é que as hifas micorrízicas absorvem o $\mathrm{P}$ a um custo metabólico para a planta inferior aos pêlos radiculares (Price et al., 1989).

A colonização micorrízica foi maior nas raízes adventícias em todos os níveis de P (Figura 4). Nas raízes seminais, a colonização máxima foi observada com a aplicação de P no nível de $125 \mathrm{mg} / \mathrm{kg}$ de

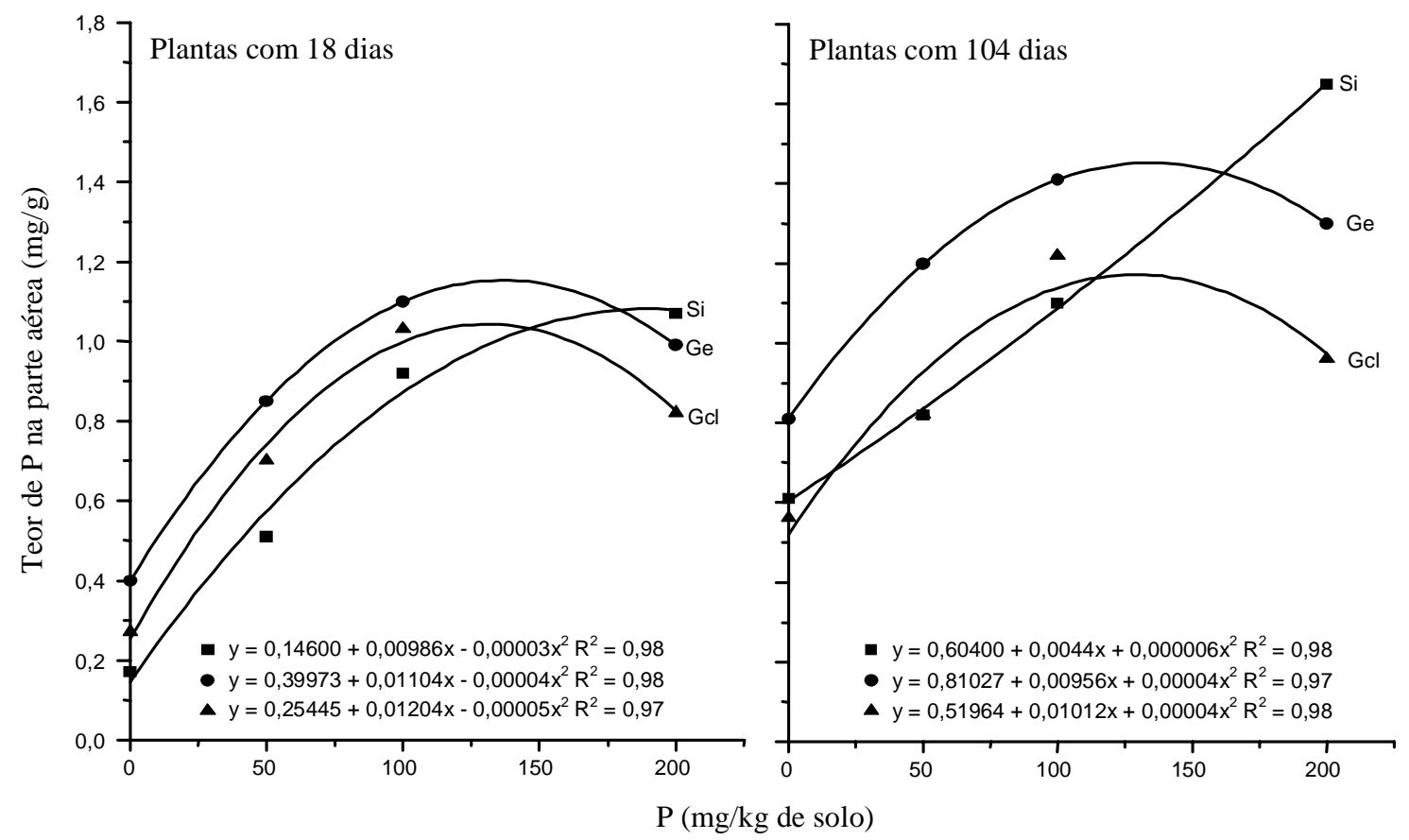

Figura 3. Teor de P na parte aérea do milho com inoculação de fungos micorrízicos arbusculares em diferentes doses de P. Ge (Glomus etunicatum), Gcl (Glomus clarum) e Si (sem inoculação). As plantas de milho foram colhidas aos 18 e aos 104 dias após a semeadura. 
solo, enquanto nas raízes adventícias ocorreu na dose equivalente de $124 \mathrm{mg} / \mathrm{kg}$ de solo. Doses acima desses valores reduziram a colonização micorrízica (Figura 4).

Nas plantas com 18 dias e sem inoculação, o teor de $\mathrm{P}$ aumentou, com as doses de $\mathrm{P}$ mostrando uma tendência a se estabilizar na dose de P igual a $200 \mathrm{mg} / \mathrm{kg}$ de solo (Figura 3). Nas plantas micorrizadas, o máximo teor foliar de $\mathrm{P}$ foi verificado com a aplicação de $131 \mathrm{mg} / \mathrm{kg}$ de $\mathrm{P}$, quando as plantas foram infectadas com Glomus etunicatum. Nas plantas com 104 dias e sem inoculação, o teor foliar de $\mathrm{P}$ variou com as doses aplicadas, enquanto nas plantas micorrizadas, o teor foliar máximo foi obtido com a aplicação de P equivalente a $128 \mathrm{mg} / \mathrm{kg}$ de solo em plantas com inoculação de Glomus etunicatum. Doses acima desse valor reduziram o teor foliar de $\mathrm{P}$ nas plantas micorrizadas.

Os resultados obtidos mostram que o peso das raízes seminais e adventícias e o número de raízes laterais primárias $/ \mathrm{cm}$ de raiz nodal aumentam com a inoculação de fungo micorrízico, porém o número de pêlos radiculares $/ \mathrm{mm}$ de raiz é reduzido. Entretanto, essa redução é suprida pelas hifas micorrízicas, que aumentam a absorção do P. Esses efeitos mostraram ser influenciados pela espécie de fungo micorrízico, pois Glomus etunicatum promoveu maior aumento no PS e PA com economia na dose de P aplicada e com aumento do teor de P na parte aérea. Doses altas de $\mathrm{P}$ reduziram esses efeitos, em duas espécies de fungos, como conseqüência da redução da colonização micorrízica. Considerando que o teor de P na parte aérea foi maior nas plantas com inoculação, verifica-se que as hifas micorrízicas foram mais eficientes na absorção desse nutriente do que os pêlos radiculares. Também foi verificado redução dos pêlos radiculares $/ \mathrm{mm}$ de raiz com o aumento da colonização micorrízica, o que indica que nas plantas com inoculação de Glomus etunicatum houve maior colonização micorrízica e maior redução no número de pêlos radiculares. As plantas com Glomus etunicatum apresentaram maior teor de P na parte

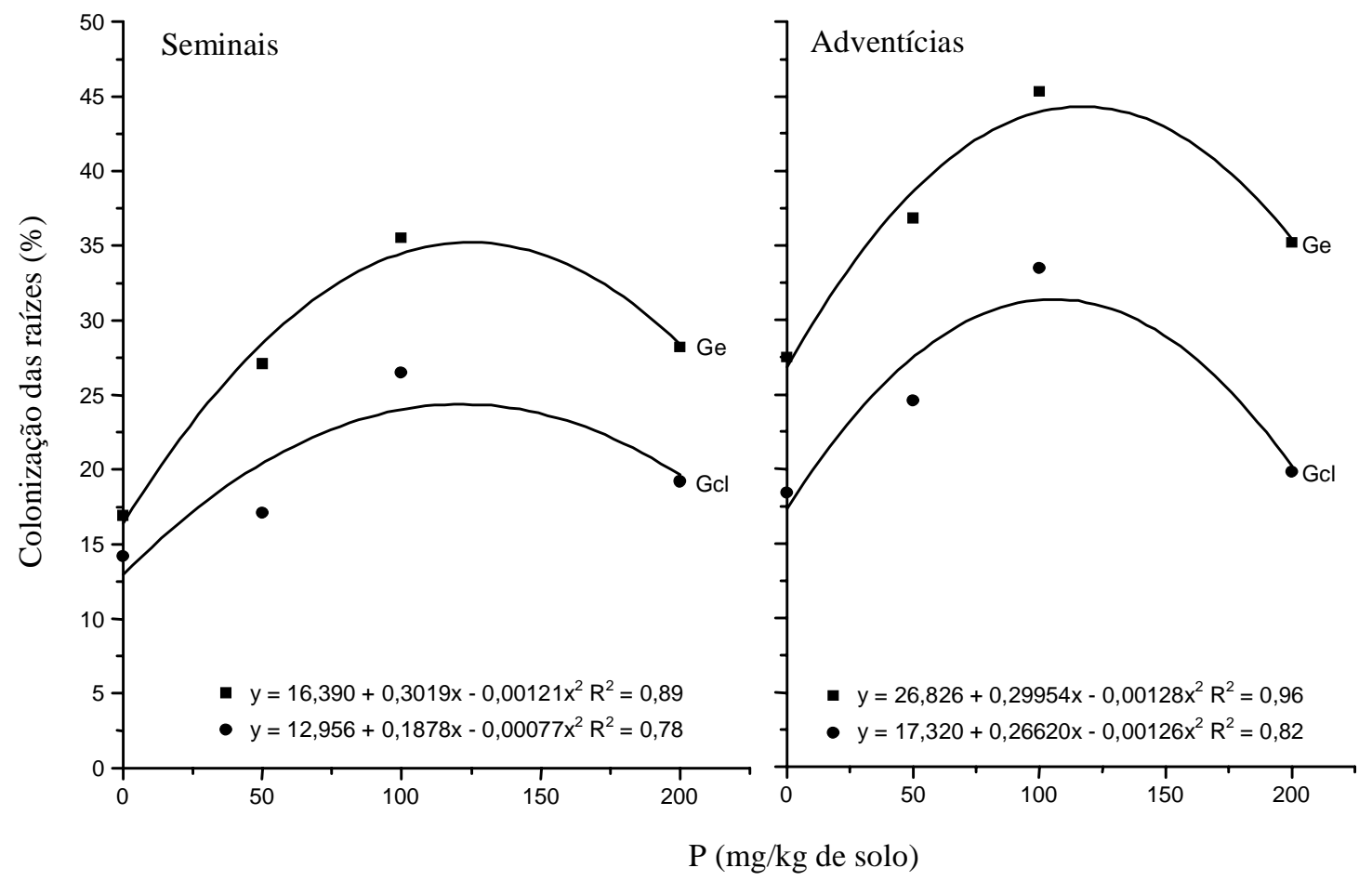

Figura 4. Colonização micorrízica do milho com inoculação de fungos micorrízicos arbusculares em diferentes doses de P. Ge (Glomus etunicatum) e Gcl (Glomus clarum). 
aérea, levando a um maior desenvolvimento desta, e uma redução na relação peso das raízes secas/peso da parte aérea seca, indicando que as hifas micorrízicas, no solo, foram mais eficientes na absorção de nutrientes para as plantas de milho.

$\mathrm{O}$ efeito mais significativo do $\mathrm{P}$ e da inoculação de fungo micorrízico sobre as raízes seminais foi constatado na morfologia do sistema radicular, uma vez que se verificou que a adição de $\mathrm{P}$ aumentou a emissão de raízes secundárias, tanto nas plantas micorrizadas quanto nas não micorrizadas.

As alterações morfológicas no sistema radicular do milho em virtude da inoculação de fungo micorrízico e adição de $\mathrm{P}$ ao solo mostraram importante implicação na aquisição de nutrientes minerais pelas plantas de milho, principalmente dos de baixa mobilidade no solo, como o $\mathrm{P}$, levando a um maior desenvolvimento da planta.

\section{Conclusões}

1. O P adicionado ao solo e a inoculação de fungos micorrízicos arbusculares afetam a morfologia do sistema radicular do milho.

2. A aplicação de P influencia a atividade micorrízica.

3. A alteração do sistema radicular influencia o teor de P na parte aérea do milho e o seu desenvolvimento.

\section{Referências}

AL-KARAKI, G. N.; CLARK, R. B. Mycorrhizal influence on protein and lipid of durum wheat grown at different soil phosphorus levels. Mycorrhiza, Berlin, v. 9, n. 2, p. $97-101,1999$

AMIJEE, F.; TINKER, P. B.; STRIBLEY, D. P. Effects of phosphorus on the morphology of VA mycorrhizal root system of leek (Allium porrun L.). Plant and Soil, Dordrecht, v. 119, p. 334-336, 1989.

BECKER, W. N.; GERDEMANN, J. W. Colorimetric quantification of vesicular arbuscular mycorrhizal infection in onion. New Phytologist, Oxford, v. 78, p. 289-295, 1977.

BERTA, G.; FUSCONI, A.; TROTTA, A.; SCANNERINI, $\mathrm{S}$. Morphogenetic modifications induced by the mycorrhizal fungus Glomus strain $\mathrm{E}_{3}$ in the root system of Allium porrum L. New Pathologist, Oxford, v. 114, p. $207-215,1990$.

BRUCE,A.; SMITH, S. E.; TESTER, M. The development of mycorrhizal infection in cucumber: effects of $\mathrm{P}$ supply on root growth, formation of entry points and growth of infection units. New Phytologist, Oxford, v. 27, p. 507514, 1994.

ELWAN, I. M. Response of nutrient status of plants in calcareous soils receiving phosphorus fertilization and mycorrhiza. Annals of Agricultural Science, Cairo, v. 38, n. 2, p. 841-849, 1993.

GIOVANETTI, M.; MOSSE, B. An evaluation of techniques to measure vesicular arbuscular mycorrhizal infection roots. New Phytologist, Oxford, v. 84, p. 489500, 1980.

GUILLEMIN, J. P.; OROZCO, M. O.; GIANINAZZIPEARSON, V.; GIANINAZZI, S. Influence of phosphate fertilization on fungal alkaline phosphatase and succinate dehydrogenase activities in arbuscular mycorrhiza of soybean and pineapple. Agriculture, Ecosystems and Environment, Amsterdam, v. 53, n. 1, p. 63-70, 1995.

HERNANDEZ, M.; CARDENAS, M. Efecto de la inoculación con micorriza en Guinea cv. Likoni. Pastos y Forrajes, Havana, v. 17, n. 1, p. 51-54, 1994.

HODGE, A.; ROBINSON, D.; FITTER, A. H. An arbuscular mycorrhizal inoculation enhances root proliferation in, but not nitrogen capture from, nutrient rich patches in soil. New Phytologist, Oxford, v. 154, n. 3, p. 575-584, 2000.

ISOPI, R.; FABBRI, P.; PUPPI, G.; DEL-GALLO, M. Dual inoculation of Sorghum bicolor (L.) Moench ssp. bicolor with vesicular arbuscular mycorrhizas and Acetobacter diazotrophicus. Symbiosis, Rehovot, v. 18, n. 1, p. 43-55, 1995.

KARAGIANNIDIS, N.; NIKOLAOU, N. Arbuscular root infection as an important factor of grapevine nutrition status: multivariate analysis application for evaluation and characterization of the soil and leaf. Agrochimica, Pisa, v. 43, n. $3 / 4$, p. $151-165,1999$.

KOTHARI, S. K.; MARSCHNER, H.; GEORGE, E. Effect of VA mycorrhizal fungi and rhizosphere microorganisms on root and shoot morphology, growth and water relations in maize. New Phytologist, Oxford, v. 116, p. $303-311,1990$.

MANE, S. S.; RAUT, R. S.; KOHIRE, O. D. Comparative performance of vesicular arbuscular mycorrhizal fungus 
and Rhizobium inoculation with groundnut. Annals of Plant Physiology, Oxford, v. 7, n. 1, p. 116-118, 1993.

MICHIGAN STATE UNIVERSITY. Department of Agricultural Economics. Department of Crop and Soil Sciences. MSTAT C: microcomputer statistical program. East Lansing, 1989. 280 p.

PHILLIPS, J. M.; HAYMAN, D. S. Improved procedures for clearing roots and staining parasitic and vesicular arbuscular mycorrhizal fungi for rapid assessment of infection. Transactions of the British Mycological Society, Cambridge, Inglaterra, v. 55, p. 155-161, 1970.

PRASAD, V.; MANJUNATH, G. T. S.; REDDY, C. N. Influence of Glomus etunicatum on growth and phosphorus uptake in Gladiolus sp. Mycorrhiza News, New Delhi, v. 11, n. 4, p. 17-18, 2000.

PRICE, N. S.; RONCADORI, R. W.; HUSSEY, R. S. Cotton root growth as influenced by phosphorus nutrition and vesicular arbuscular mycorrhizas. New Phytologist, Oxford, v. 111, p. 61-66, 1989

SARRUGE, J. R.; HAAG, H. P. Análises químicas em plantas. Piracicaba: Esalq, 1974. 56 p.

THOMSON, B. D.; ROBSON, A. D.; ABBOTT, L. K. Mycorrhizas formed by Gigaspora calospora and Glomus fasciculatum on subterranean clover in relation to carbohydrate concentration in roots. New Phytologist, Oxford, v. 114, p. 217-225, 1990 